\title{
Design of Chiral Ligands for Asymmetric Catalysis
}

\author{
Andreas Pfaltz ${ }^{\star}$
}

Keywords: Allylic substitution · Asymmetric catalysis · Enantioselective hydrogenation · Oxazoline ligands

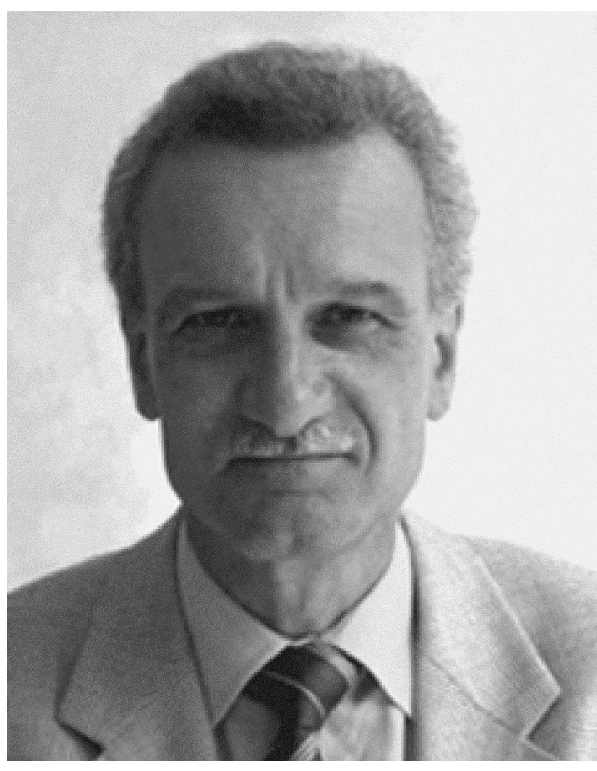

Andreas Pfaltz

In the mid 80 s we developed a new class of chiral bidentate nitrogen ligands for asymmetric catalysis, the $\mathrm{C}_{2}$-symmetric semicorrins 1 (Fig. 1) [1]. In these compounds, the two substituents at the stereogenic centers are located in close proximity to the metal center and, therefore, have a distinct, direct effect on a reaction taking place in the coordination sphere. The high enantioselectivities induced by semicorrins in the copper-catalyzed cyclopropanation of olefins and cobalt-catalyzed conjugate reduction of $\alpha, \beta$-unsaturated carboxylic acid derivatives, prompted us and a number of other groups to develop structurally

${ }^{*}$ Correspondence: Prof. A. Pfaltz Departement Chemie

Universität Basel

St. Johanns-Ring 19

$\mathrm{CH}-4056$ Basel

Tel.: +41612671108

Fax: +41612671103

E-Mail: Andreas.Pfaltz@unibas.ch

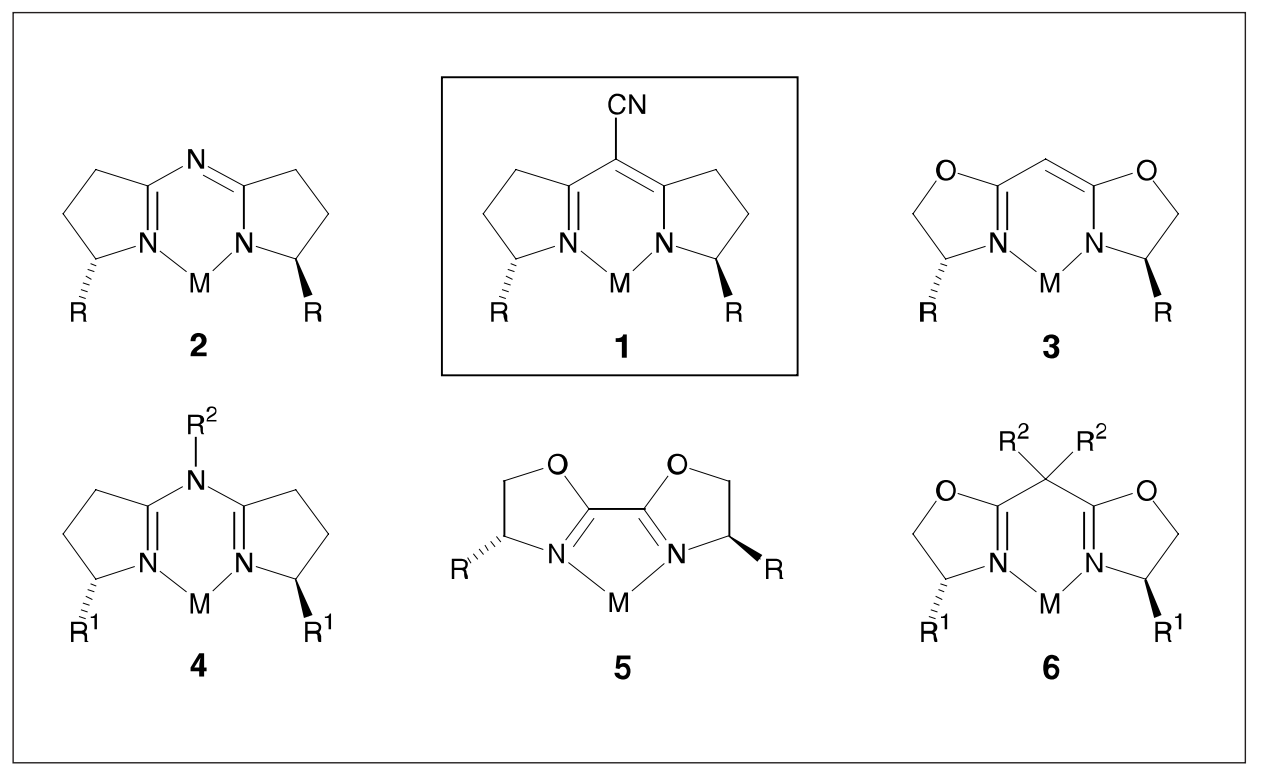

Fig. 1.<smiles>[R]C1COC2=C(c3ccccc3P([R7])[R7])N=[N+]21</smiles>

7

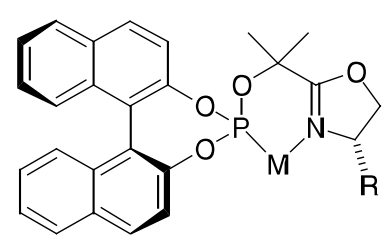

8

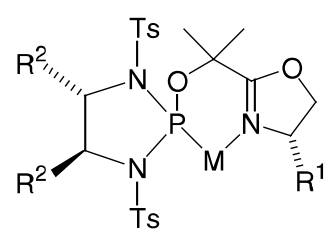

9

Fig. 2.

related ligands such as the aza-semicorrins $\mathbf{2}$ and $\mathbf{4}$ and the bisoxazolines $\mathbf{3}, \mathbf{5}$, and $\mathbf{6}$. Especially bisoxazolines of type $\mathbf{6}$ have proven to be highly versatile ligands for the enantiocontrol of a wide range of metal-catalyzed processes [1][2].

In the course of our studies on Pd-catalyzed allylic substitution, we changed the direction of our research toward unsymmetrical P,N-ligands such as 7 (Fig. 2). We hoped that the different electronic trans influence of the $\mathrm{P}$ - and the $\mathrm{N}$-atom in these ligands could be exploited for controlling the stereochemical course of allylic alkyla- tions, which indeed proved to be the case [3-6]. The modular construction of phosphinooxazoline (PHOX) ligands made it possible to optimize their structure for a particular substrate or reaction. With ligands of type $\mathbf{8}$ and $\mathbf{9}$, which were developed based on mechanistic criteria, high regio- and enantioselectivities could be induced in Pd-catalyzed allylic substitutions with monosubstituted allyl substrates [7]. Recently, we also developed an efficient screening method that allowed us to identify suitable ligands for kinetic resolution of allylic esters. 


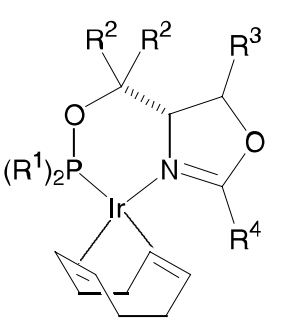

$\left(R^{1}\right)$

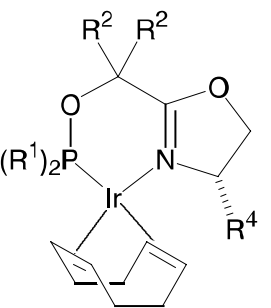

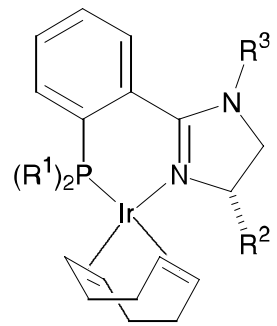

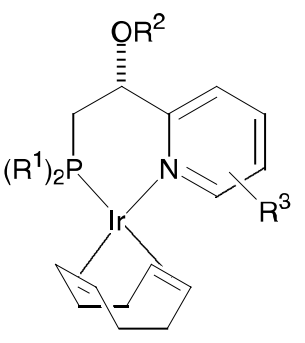

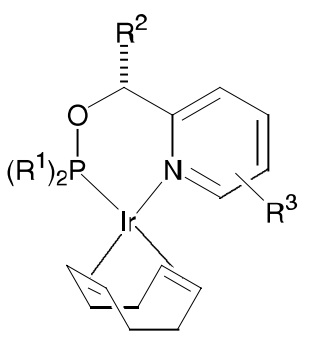

Fig. 3.

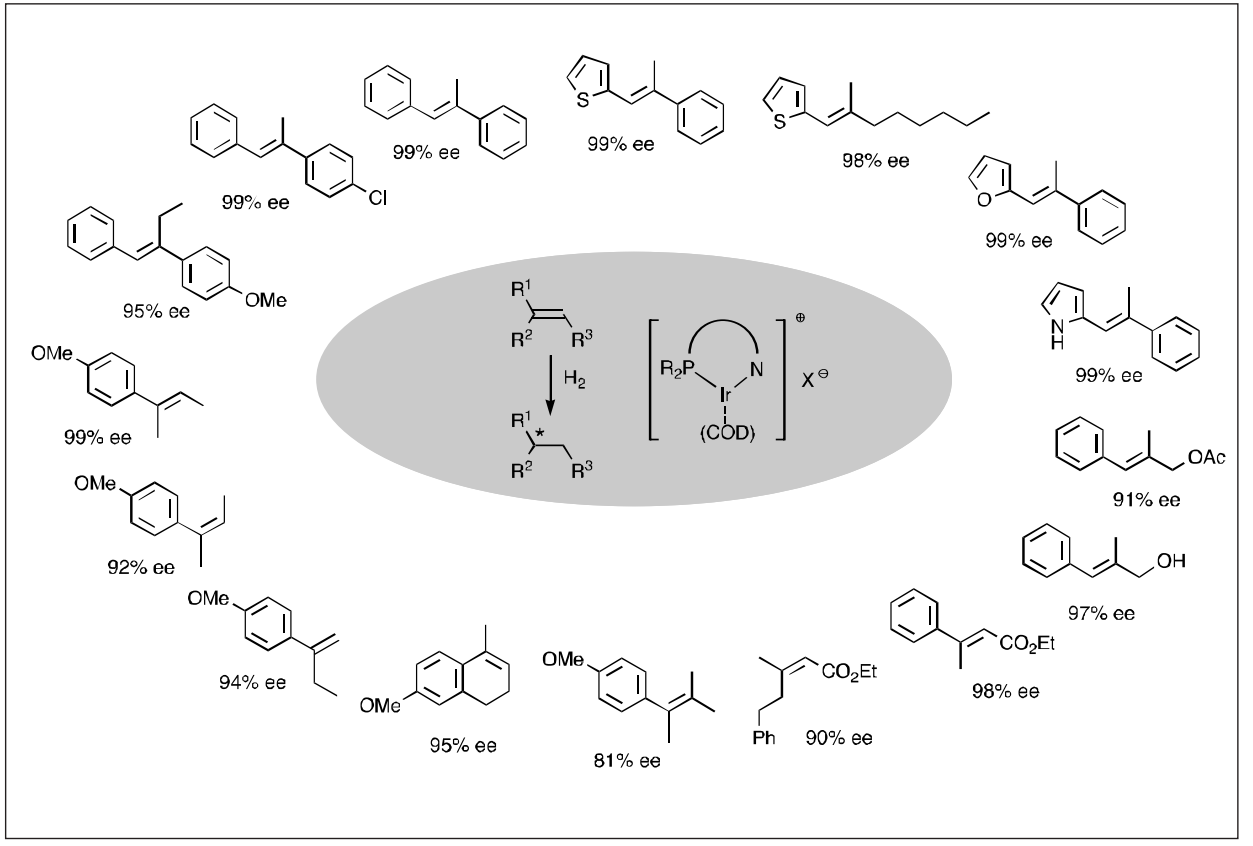

PHOX ligands have been successfully applied in various other metal-catalyzed processes, such as Heck reactions, $\mathrm{Cu}$-catalyzed conjugate additions to enones and Ircatalyzed hydrogenation of imines and olefins [6]. Extensive evaluation of many classes of chiral P,N-ligands has led to a set of Ir complexes that have considerably expanded the scope of asymmetric hydrogenation (Fig. 3) [8]. In contrast to Rh and Ru catalysts, which only perform well with alkenes bearing a polar coordinating group next to the $\mathrm{C}=\mathrm{C}$ bond, these Ir complexes catalyze the hydrogenation of various unfunctionalized and functionalized, acyclic and cyclic olefins with excellent enantioselectivity and high turn-over numbers (Fig. 4).
[1] A. Pfaltz, Acc. Chem. Res. 1993, 26, 339.

[2] A.K. Gosh, P. Mathivanan, J. Cappiello, Tetrahedron: Asymmetry 1998, 9, 1.

[3] P. von Matt, A. Pfaltz, Angew. Chem. 1993, 105, 614; Angew. Chem. Int. Ed. 1993, 32, 566.

[4] J. Sprinz, G. Helmchen, Tetrahedron Lett. 1993, 34, 1769; G. Helmchen, S. Kudis, P. Sennhenn, H. Steinhagen, Pure Appl. Chem. 1997, 69, 513.

[5] G.J. Dawson, C.G. Frost, J.M.J. Williams, S.J. Coote, Tetrahedron Lett. 1993, 34, 3149; J.M.J. Williams, Synlett 1996, 705.

[6] G. Helmchen, A. Pfaltz, Acc. Chem. Res. 2000, 33, 336.

[7] R. Prétôt, A. Pfaltz, Angew. Chem. 1998, 110, 337; Angew. Chem. Int. Ed. 1998, 37,
Fig. 4.

323; R. Hilgraf, A. Pfaltz, Synlett 1999, 1814.

[8] P. Schnider, G. Koch, R. Prétôt, G. Wang, F.M. Bohnen, C. Krüger, A. Pfaltz, Chem. Eur. J. 1997, 3, 887; A. Lightfoot, P. Schnider, A. Pfaltz, Angew. Chem. 1998, 110, 3047; Angew. Chem. Int. Ed. 1998, 37, 2897; A. Pfaltz, J. Blankenstein, R. Hilgraf, E. Hörmann, S. McIntyre, F. Menges, M. Schönleber, S.P. Smidt, B. Wüstenberg, N. Zimmermann, Adv. Synth. Catal. 2003, 345, 33; W.J. Drury III, N. Zimmermann, M. Keenan, M. Hayashi, S. Kaiser, R. Goddard, A. Pfaltz, Angew. Chem. 2004, 116, 72; Angew. Chem. Int Ed. 2004, 43, 70. 